\title{
MIDAS
}

Museus e estudos interdisciplinares

\section{Intertwined artistic practices: critical remarks on collaboration across fields of knowledge}

Práticas artísticas intersticiais: reflexões críticas sobre colaboração entre campos de conhecimento

\section{Maria Manuela Lopes}

\section{(2) OpenEdition}

\section{Journals}

\section{Edição electrónica}

URL: http://journals.openedition.org/midas/856

DOI: $10.4000 /$ midas.856

ISSN: 2182-9543

\section{Editora:}

Alice Semedo, Paulo Simões Rodrigues, Pedro Casaleiro, Raquel Henriques da Silva, Ana Carvalho

\section{Refêrencia eletrónica}

Maria Manuela Lopes, «Intertwined artistic practices: critical remarks on collaboration across fields of knowledge », MIDAS [Online], 5 | 2015, posto online no dia 04 dezembro 2015, consultado no dia 10 dezembro 2020. URL : http://journals.openedition.org/midas/856 ; DOI : https://doi.org/10.4000/ midas.856

\section{Este documento foi criado de forma automática no dia 10 December 2020}

\section{cc) (1) (ㅇ)}

Midas is licensed under a Creative Commons Attribution-NonCommercial-ShareAlike 3.0 International License 


\section{Intertwined artistic practices: critical remarks on collaboration across fields of knowledge ${ }^{1}$}

Práticas artísticas intersticiais: reflexões críticas sobre colaboração entre campos de conhecimento

Maria Manuela Lopes

\section{Introduction}

In accordance with the post-modernist tradition, the artist is transformed into a producer of processes, contexts and experiences, revising the concept of authorship. The created work requires an active reception or a perceptive interpretive process by the participant/ audience where meaning is emergent and negotiated from the process of experience/ interaction. Similarly, according to van Dijck (2002) '(multi)cultural' practice of science communication acknowledges the increasing cultural diversity in scientific and academic populations throughout the world, including countless disciplines/professions and the public to be simultaneously interweaved in the construction and negotiation of science. The collaboration between artists and scientists is no longer a surprise and is validated as a strategy in the art world (Kemp 2011, 279). Meaning in an artwork is constructed from active audience participation through the engagement with the field of artistic communication in a specific context. In the actual art scene the glass walls between artworks and audience are shattered, and with those, the connections between the artist and the studio and further the artist as the single author. 


\section{Where's the gap? The artist, the scientist and science communication}

2 Until the Renaissance, art and science were considered unified in the western world. Due to various socio-economic factors, the developing split of the comprehensive "natural philosophy" was then manifested by the separation into the discipline of art and the discipline of science in the educational system. By depicting the two disciplines as separated and uninformed of each other, Snow (1959) started an on-going public debate about the division of the community of scientists and the community of specialists of the literary and artistic world.

The actual two cultures divide dates back to the 19th century, or more precisely, to the 1830 s when the term 'scientist' was coined analogous with 'artist'.

A split in educational degrees (...) led to a subsequent split in professional socialization - a division of tasks where ethics, aesthetics, history and culture became the domain of one group of scholars, whereas another group was exclusively concerned with understanding and controlling the laws of nature. (van Dijck 2002, 2)

3 As $\operatorname{Kemp}(2009,32)$ contends, specialization became the 'real enemy of understanding' and at present we may find many gaps, as each academic/professional subject became almost a laboratory with its own hermetic language, professional protocols and technical proficiencies. Hybrid disciplines such as molecular biology or computer science blurred the binary cultural mode and can no longer be categorized in any one side of the gap, as they require an aptitude to think across boundaries.

4 As van Dijck asserts (2002) 'bridging the gap' between arts and sciences, implied a translation between experts and untrained communities. Translators were needed to mediate between the specialized jargon of scientists and an illiterate public. In actual panorama of digital access to information, 'the translations' and the media are no longer mediating between experts and lay persons, but are actors in processes of construction and dissemination (van Dijck 2002). Specialization of knowledge exists in all areas but it is no longer passively disseminated but actively available and negotiated. Science communication is negotiated in many cultural arenas, from the laboratory to art works. Scientific and technological practices, materials and knowledge when addressed in informed and inspired representations, metaphors, contexts and aesthetic experiences became part of an ecology of co-construction of knowledge. Science as art are part of culture and no monolithic fields, they may seem opposite dominated by technological and data or subjectivity and emotion but they are networks of people interested in life conundrums that depend on open-ended inquiries, attempts, failures and learning in a feedback loop between doing, thinking and feeling.

\section{Collaboration: breaking down borders}

The rapidly growing complexity of knowledge required specialization in order to advance. The intersection of disciplines naturally presents the question of collaboration. As I have been using different media in my artistic endeavor I value teamwork, since practical circumstances often require a number of people to create a finished work. Also in approaching the themes I am exploring (such as memory, identity and nature) from 
different perspectives, I feel the need to consider technological developments and scientific and medical processes dealing with research and redefinition of concepts in these different fields, as well as, what cultural critics and commentators in the humanities have to say about the meaning and processes leading to these discoveries and innovations and their impact on culture and society.

Collaboration to me has been always the result of my self-motivation and personality match between others and me, and was largely determined by empathy and capability to communicate as a major factor. ${ }^{2}$ Science communication teams ${ }^{3}$ where always very cherished as skilled individuals that already know the interstices of the research institutes and also the de-codification language necessary for the success of the dialogical relationship established. The form of collaboration and my role as artist depends on the project framework, changing from creator, coach, technician and apprentice, or participant director, but always the driving force. In previous art/sciences collaborations and even co-authorship the contribution to the production of the artworks unfolded with the scientists supplying their expertise and then succumbing to their occupational commitment. In order to construct challenging new art projects boundaries and borders need to be transgressed, therefore collaborations as co-authorship may be a non productive model, ending up in the scientists used as specialized technicians and artists used as visual producers and image enhancers. My experience within these collaborations led me to devise a method of interdisciplinary work in a specific context of art-science collaboration in which my art project is situated.

In Six Stories from the End of Representation, Elkins $(2008,18)$ proposes an exercise to build bridges between the humanities and the sciences. This involves allowing them to stay side by side telling stories in their own languages, thus forcing the viewer to decide which threads may tie the presented images together. In my work, fragments of text, images, sound and time are enacted and re-enacted into art practice, during which the scientific materials are re-framed within cultural and social conventions.

\section{Art as research in the neuroscience laboratory}

8 My practice-based research (Lopes 2013) was in the Instituto de Medicina Molecular and Hospital Santa Maria, in Lisbon. This provided a unique and complementary scientific/ laboratory/artist studio in which to develop a progressive and situated practice-based inquiry into how memory loss is scientifically researched - this opportunity to follow the scientific path of Alzheimer disease research was an enriching and humbling experience. Science and health philosophers Berg and Mol (1998) claim that medical and scientific investigation is based on practices of construction, assemblage and incorporation of techniques, habits, ideas, images and conversations. This represents my concept of an archive, envisioned as a network of four intertwined 'archival spaces' (fig. 1):

1. the patient;

2. the art studio;

3. the Alzheimer's research laboratory;

4. the cellular and molecular research laboratory. 


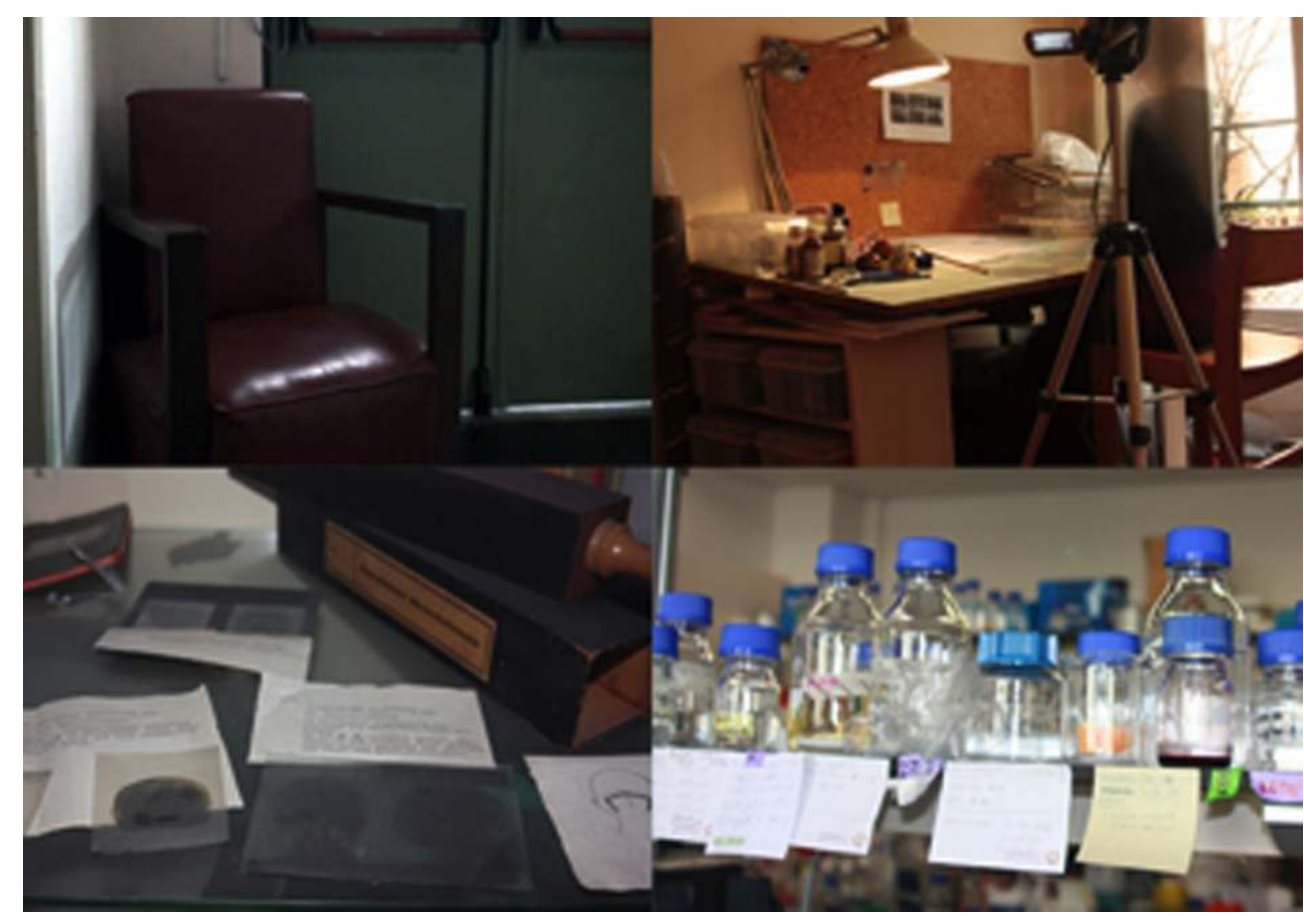

Fig. 1 - Maria Manuela Lopes, 2009. 'The Four Virtual Archival Spaces'

Photography by Maria Manuela Lopes (c)

9 In this process I have documented the assessment and categorization of Alzheimer's patients and their exposure to various assessments and therapies. ${ }^{4}$ I have also documented molecular and cellular research laboratory procedures and collected laboratory materials. In order to maintain a common thread when approaching these spaces, methods have focused on neuroscientific diagnostic images (MRI and PET scan), graphs, diagrams, notes, models, photographs, instruments, physical space conditions and hybrid forms of these, and establishing a critical link to art practice. In laboratory studies these visual approaches are designated representational strategies or practices (Lynch and Woolgar 1990, 1-18).

10 My engagement with the scientific research renders the process of archiving contingent on my subjective experience. This contextual immersion depends on conceptualization and reflection of my artistic role in their scientific ground. My work therefore involves stimulating scientists in this specific field of neuroscience to adopt a visual approach to their research topic.

11 My work is based on the premise, following Tulving (2002) and Conway (2005), that memories are rehearsed performances of reconstruction, narrated and practised, rather than simple access to fixed archived data. The sensory details and images that are held, comprising the feeling, context and meaning of experiences, become linked in the process of remembering to form memories, rather than existing innately as memories.

12 It became necessary for me to explore memory, in the sense of active construction, in order to reflect on strategies of representation and technologies that are fundamental to my art process and also sustain part of current scientific research. Images, mainly those produced with the help of a camera, have become almost synonymous with memory and remembrance in the world of visual culture. Photography and video worked in tandem to record a timeline of the experience of my artistic residence: firstly, by picking up the fragments of space and time that are constructed in the gestures and stories - so similar 
and yet so different - unfolded by people including physicians, researchers, patients, care-givers and technicians; and secondly, through the intrinsic relationship of those media to reality and truth in the descriptions of the experiences (memories) that we so dearly (in most cases) store and so firmly believe.

Art based on neuroscientific representational practices and metaphors should be not be seen as merely illustrative of and subordinate to molecular or diagnostic scientific inquiry. Visibility in art is not bound to scaling down of reality or illustrating an outside world; it creates realities as much as autobiographical memory. I propose instead that art, establishing the link between neuroscience research and culture, should be imagined as a fictional equivalent to the manoeuvres of autobiographical memory.

Representational strategies are catalogues or archives of categories or systems, by which life and diseases are ordered in the biological sciences. They may be considered as a way of translating the invisible under-structure of life to a visual domain of notation and drawing. The sign becomes an outline of the cultural code, abbreviating the materialization of an idea into visual form.

\section{Networks}

Medical assessment through visual evidence is associated with specific cultural practices and 'modes of seeing' (Sturken and Cartwright 2002, chapter 8). Science has thus been interpreted as a process of generating ever more accumulating and circulating 'drawings', rather than observing the natural world. ${ }^{5}$ This clearly applies to medical practices represented by images and text, in which the performances behind their construction vanish like a memory event and are replaced by a diagram of the sensual path the brain has experienced through that same time/place action. When these are published, shared in meetings and circulated in the media as 'immutable mobiles' (Latour 1998, 426), these inscriptions become self-referential and evocative of other, previous representations ${ }^{6}$ rather than the messy, sensual material reality we belong to.

My visual research in the Alzheimer's research clinic seeks to define the loss of memory, the disease, and the autobiographical construction of the self. How can autobiographical memory be evoked by scientific representational practices? I use Latour's set methodology to examine my practice. No matter how clean and tidy a scientific fact may seem it is a result of a series of mediating actions built on the consensus of a multidisciplinary community.

Bruno Latour, Michel Callon and John Law developed the actor-network perspective (or theory, i.e. ANT) on scientific knowledge, taking Foucault's power/knowledge understanding as a starting point but focusing on networks. Actors may be objects as well as people. The network suggestion allows entities to circulate in the laboratories and be exported as scientific facts or representations following processes of scaling down, inscription and construction. The conditions of art/science 'collaboration' in this project derive from my understanding and appropriation of metaphors from the ANT allowing a free circulation and non-hierarchical use of representational strategies from each archival space. The word collaboration when used can be understood as facilitation.

Networks are intended to connect laboratories to chains of actors in different spatial locations and to address the contradiction that so few people seem to embrace the world: 
The word network indicates that resources are concentrated in a few places - the knots and the nodes - which are connected with one another - the links and the mesh: these connections transform the scattered resources into a net that may seem to extend everywhere. (Latour 1987, 180)

Latour (1987) emphasizes the central role played by images such as inscriptions and material artifacts in consolidating the networks ${ }^{7}$ established between laboratory and the outside community. He calls these delegates 'immutable mobiles', which should provide important information of the places and people concerned.

\section{Research methodologies}

Experience in the clinical and scientific spaces is oriented to observation, collection and video and photographic captures of repeated gestures, sentences, materials produced, archival strategies; this includes recording the neuropsychological assessment sessions and part of the clinical research and aftercare, as well as digitalizing the material outputs of their direct performance (drawings and handwritten narratives). This process is considered an enactment of the archive. ${ }^{8}$

21 I have recorded myself undergoing comparable self-assessment sessions in the studio space, which involves the production of further drawings, hand-written sentences, sound and gestures. These sessions included revisiting recordings of the laboratories and patients, as well as visual materials produced, and contrasting them with the recordings of myself, and their respective outcomes. This process is considered a re-enactment of the archive. Decisions about editing and juxtaposition were informed by reading neuroscientific studies on autobiographical memory and Alzheimer's disease, which gave clues to editing rules. This re-enactment of the archive was intended to establish a critical gap between the original scientific coordinated performance and the parallel cultural and subject-driven practice.

Cognitive psychological theory on autobiographical memory informed by other fields of neuroscience is rich in metaphor and suggestions for a visual approach; I have applied some of its vocabulary to descriptions of my installation and time-based work. Thus, to describe the characteristics of autobiographical memory, terms such as multidimensionality, coherence, continuity, reconstruction, representation, narrative or perception could be included.

23 To facilitate access to the patients' space in a diversified approach I accompanied several patients under various clinical and therapeutic approaches. Written and oral informed consent was obtained from participants, after clearance from the ethical committees. ${ }^{9}$ Personal experience on location allowed me to focus on my topic, share moments of tension, hope and drama, and to observe and participate in moments of corporeality. Eight patients undergoing different innovative Alzheimer's therapies were followed during the stages of their clinical journey. This meant accompanying the pre-defined designs of the medical investigation set up as well as similar ethical protocols, thus circulating in the Alzheimer's research laboratory space.

The cellular and molecular laboratories and their lab group meetings were visited regularly, and data collected (video, photography records and inscriptions) from observation of their investigations of molecular and cell death mechanisms. 


\section{The Therapy} the studio and research methods included: performing rituals; making instructional performances; exercises such as copying simple forms, spotting patterns and rhythms of letters and numbers; establishing items in the appropriate places, making relationships between one archive and another; editing video and photographs; travelling and translating; finding order and remembering. The artefacts produced in the studio were not conceived as an installation work but are the residue of the research process. In the process of translation from an orchestrated scientific approach towards the more associative montages of the re-enactments, I propose the use of fresh personal narratives or an intertwining of the imaginary with the real stories of the 'actors' (Latour's term), thus blurring the boundary between the real and the invented and approaching more closely the associative power of autobiographical memory.

I use deceptive and disappearing techniques including paper works, cast wax objects, video fades and semi-erased chalk inscriptions as metaphors for the dialectic relationship of reconstruction and decomposition of memory and the persistence of presence/absence in the memory of the materials. The works produced by these techniques resemble diagrams found in laboratory protocol science manuals, neuropsychological assessments, children's 'how to draw' books and cognitive stimulation therapy exercises. Understood as part of this procedure are forms that are invisible at first but gain substance over time, such as meaning in diagnostic images, as are other forms such as laboratory records. Science and art may be bridged via these links (fig. 2).

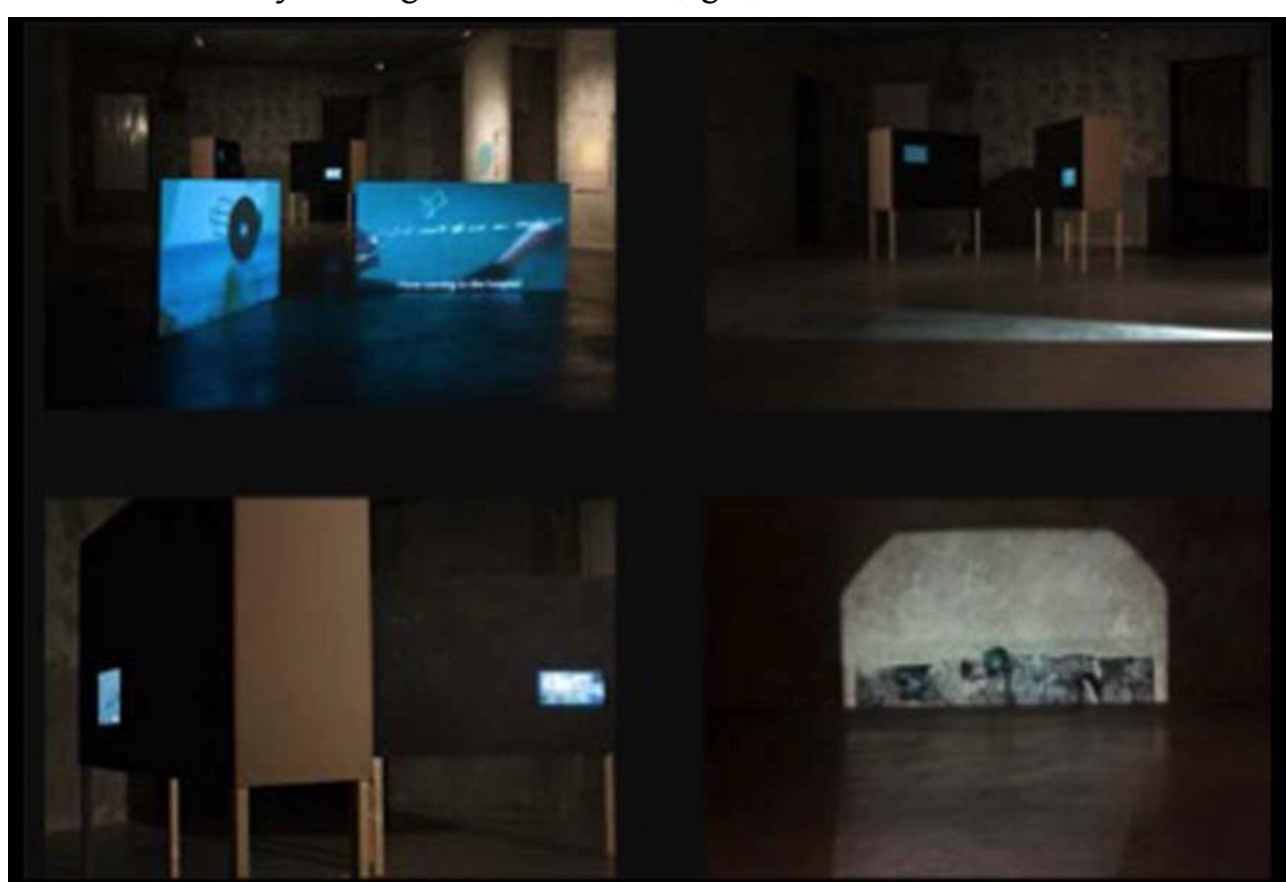

Fig. 2 - Maria Manuela Lopes, 20112, The Therapy. Exhibition Uma Coisa Entre Muitas. Museu Nacional de Historia Natural e da Ciência, Lisbon

PHOTOgRAPHY BY MARIA MANUELA LOPES @

In therapy sessions, in my studio and in the laboratory, schematic type of figures grew repeatedly and slowly from recurring, rehearsed actions. Such methodology is therefore 
responsive to observations made in the actual laboratory context, in therapeutic guidelines, in my studio practice and in textual understanding of how autobiographical memory functions. My interest in therapeutic neuroscientific guidelines arose from the ways in which these challenges and descriptions may be indirectly incorporated into video sequences, as a transforming layer of the image sequence that actively engages affect. What emerged from these words and images represented a heightened synergy between the optical and linguistic type of images. Transforming this working process into an installation work has been challenging: presentation of The Therapy has been planned in various formats including a different series of work appropriate for a large space, whether a gallery or some other place.

When re-enacting the archive as part of my methodology and also as a therapeutic strategy - a repetition of previous actions - I observed that video depicts the body and action flowing and changing over time. Like photography, video is often understood as a technology that is designed to frame and document 'the real'. The images I captured, however, were influenced by the attention I gave to the object of my gaze, my ideological imperatives and ethical sensibilities, and also by the logic and formal qualities of the setting and the technology itself.

The audio-visual data I recorded in the laboratories allows me to examine coordination and mutual elaboration through various semiotic resources and the environment in which the action takes place, exploring how actors constitute their social world though juxtaposition using language, body orientation, gesture, and material structure in the environment. Examination of the details in the laboratory images that the camera inadvertently picked up, such as random objects left lying on work surfaces and background noise, highlights the similarities between everyday, generic human activities and specialized, scientific practices. ${ }^{10}$

30 As suggested by previous definitions, nothing is irrelevant; everything is potentially important. For example I might assign equal importance to the human gesture of transferring chemicals carefully between glass vials and a digital image obtained via measuring some qualities of the different amounts of the substance after the first step/ action has been disregarded. According to Latour's theories, not all 'actants' are the same: 'their differences rest in their form'. Latour described how, for example, a 'tag', such as a simple post-it note, can become an actor when given figuration. Materiality is consequently vital in the establishment of a relationship. Laboratory instruments have technical limitations, and these limitations condition what can be communicated to others in the network. Equally the technical specifications of my stills camera or video camera impact on the image quality, aspect ratio of the frame, data capture and physical proximity to laboratory events. Every actor is part of a complex montage. Every Petri dish or MRI scans, or even a light in a room or a postcard on a refrigerator door is a possible event capable of translation. Strength in building science comes from this flux of interactions; 'cascades of inscriptions' which in turn become chains of translation.

31 Following scientists in action is central to Latour's rationale (1987). His examination of what constitutes an actor enables us to not only follow scientists in action but also 'follow the actors' (2005). In his view it matters little whether one follows a scientific process at the beginning, middle or end of its progress because the smallest 'actant' has equal value. As noted by Latour and Woolgar (1986) and Latour (1987), the effort to clarify and refine data from artefacts is central to laboratory practice. In a studio or an exhibition setting 
almost the opposite is done, by reintroducing surrounding actions, sounds, and using montage and juxtaposition to evoke the complex workings of the systems that enable production of these facts (and the complex system of memory work), rather than the facts that science claims to have achieved. 'Looking at' and 'seeing' not only relate to what goes inside the frame, but also to actions that arise from memory (experience) in the management of things/objects. Seeing takes place at a translational level and relates to the establishment of collective significance. Process thus becomes a crucial concept, and these ideas of memory and process are integral to my art making.

The use of video and photographic material produced by both the scientists and myself acts as a realist dimension that provides associational narratives and histories. It evokes a laboratory diary, referring to the path of my own experience throughout the research. The body of work uses mixed media including photography, cast objects and video drawing in an installation artwork to explore sensual and embodied spatial potential. The aim is to implicate my audience both emotionally and bodily, encouraging them to consider how my experimental and witnessing experience influences their perceptions, and to reflect on their own corporeality and conscious 'time travel' (Tulving's concept). By this, I facilitate a fragmentary and multimodal approach to re-enactment of several possibly related events that informs a fleeting sensual and cognitive experience. This, I feel, should extend the institutional panoptical gaze on the patient, transforming my personal experience into a complex perceptual and embodied experience that, like autobiographical memory as I understand it, takes place in the present.

\section{Memory and narrative in The Therapy}

This installation represents a culmination of my thinking about whether the autobiographical memory process can be evoked. It was realised following discussions, presentations and reflection on previous work alongside studio exploration of therapeutic strategies such as reminiscence therapy. It does this by drawing viewers in to become participants in the creation of access to their own experienced and reflective spaces, in which the body, their actions, their attention and their memory are acknowledged. The complicity of spectators is a necessary condition for my praxis: the work is mediated by the audience, who are thus introducing consciously their own actions and reactions to the experience.

The spectator enters The Therapy at an arbitrary point in the video sequence and may leave at will. I chose to do this rather than having a clear starting and finishing point in order to empower the audience's role in the meaning of the work. The spectator ${ }^{11}$ must decide the appropriate duration of the piece and ensure that the whole montage has been seen. The indeterminate duration also negates the possibility of a fixed narrative sequence. Narrative structures in stories we tell, are told, or witness - and apparently in the way our memory operates - traditionally function as a guide to a sequence of events, often with the expectation that it will follow a path and offer a degree of closure. In denying such a sequential structure, I encourage the audience to construct its own meaning from the footage, based on the fragments of data available. I also aim to reinforce the importance of the formal aspects of the work to bring complexity to the issue of the representational strategies it uses. To achieve this the viewer must be drawn into a self-reflexive engagement with how they come to define these parameters. The work attempts to make spectators aware that their conceptions and operation of memory 
are always contingent and that this divide is never fixed but subject to continual modification. Only by allowing the audience to engage and disengage with the science/art dyad is it possible to destabilise and bridge this 'divide'.

\section{Affect and effect}

The inscriptive devices of the laboratories, patients and research staff, the source site, the video clips captured in the laboratories, the photographs, the texts, the presentational sites, the spectator, and myself have all been regarded as 'actors', producing traces of association (Latour 2005, 71). Latour's term is an element that acts upon, affects and is affected. The installation The Therapy explores not the dislocation of the action but the affect and effect of the network of traces joined by the viewer in a dialectical process. The spectator (including the artist, science communicator and the scientists who collaborated in the production of the installations) is the site of the production of meaning; the one who engages in the bridging of the art/science discourse and who also observes his or her own actions. The spectator moves through the exhibition space re-enacting their feelings and memories; in this movement or dislocation meaning is reformulated, reconstructed, and renewed. These events as practice could be understood as multi-modal re-enactments ${ }^{12}$ or performances of autobiographical memory, which according to Foucault exercises a form of self-control.

This work is an examination of memory and how we process 'time travel' or autonoetic awareness (Tulving 1972). The memory or witnessed events accelerate, the frame rate increases, time shifts, and reality gives way to memory. When we witness and recall an event we operate in a similar way. What we quantify as time, exact minutes and seconds, is displaced once it is recalled from our organic memory bank. Places, spaces and memories are not static, concrete objects but areas with a distinctive reference to each and every individual.

Responses to the images produced in the enactment of the archive reveal affective experiences. My aim is to preserve the impact in order to provide a moment for affective encounter on the part of the viewer that extends the implicit drama of Alzheimer's disease and explores other narratives besides those directly implicated in the image source. I consider that affective responses precede and/or are a substitute for cognition and representation. As Latour argues, it is not just individuals that act and affect; inanimate objects as actors also act in forming social contexts for 'the type of agencies participating in interaction seems to remain wide open' (Latour 2005, 22 and 236). objects, drawings and video sequences do not exist as artworks independent of a selected presentational context in which they are presented. On a desk in a neuroscience laboratory the images/objects resonate with the neurological research subject and appear as metaphors, inspecting tools, or therapeutic devices, as well as, in Latour's terms, inscriptive translational exchange materials. Sometimes the visual forms appear to represent emotive subjects that produce fear or compassion, but this is experienced through reasoning rather than viscerally in the moment of confrontation. Ultimately, and as an autobiographical memory process, it is in the subject's body rather than in the artwork that affective traces can be found.

I decided on a complex and ambiguous approach to storytelling/presentation, feeling that a 'truthful' representation of my practice needed to present multiple bodies of work, to explore multiple materials, to collide and juxtapose. I created several parallel experiences 
of linear, mechanical time passing, but at a different rate from that of the original action and with juxtaposed storylines in an altered order, in tandem with fleeting chalking inscriptions on the supporting black boards (fig. 3). This allows an observer to engage with the tension between performance and repetition, event and memory that is central to the re-enactment as a representational form. I addressed and explored ways in which recordings and projection (enactment and re-enactment of the archive), both as a concept and as an artistic method can replicate and extend the medical gaze. I also, in the context of my research, followed the path taken by a patient when approaching the institution (The Approach, The Assessment, The Archive and The Therapy) so that my installations may be understood as an alternative to the representational process of research into, and treatment of, Alzheimer's disease. This creates the potential for an agency to approximate the functioning of autobiographical memory. It is my contention that the work is enriched and given additional resonance through such an approach, and that it is a comprehensive account of a research process.

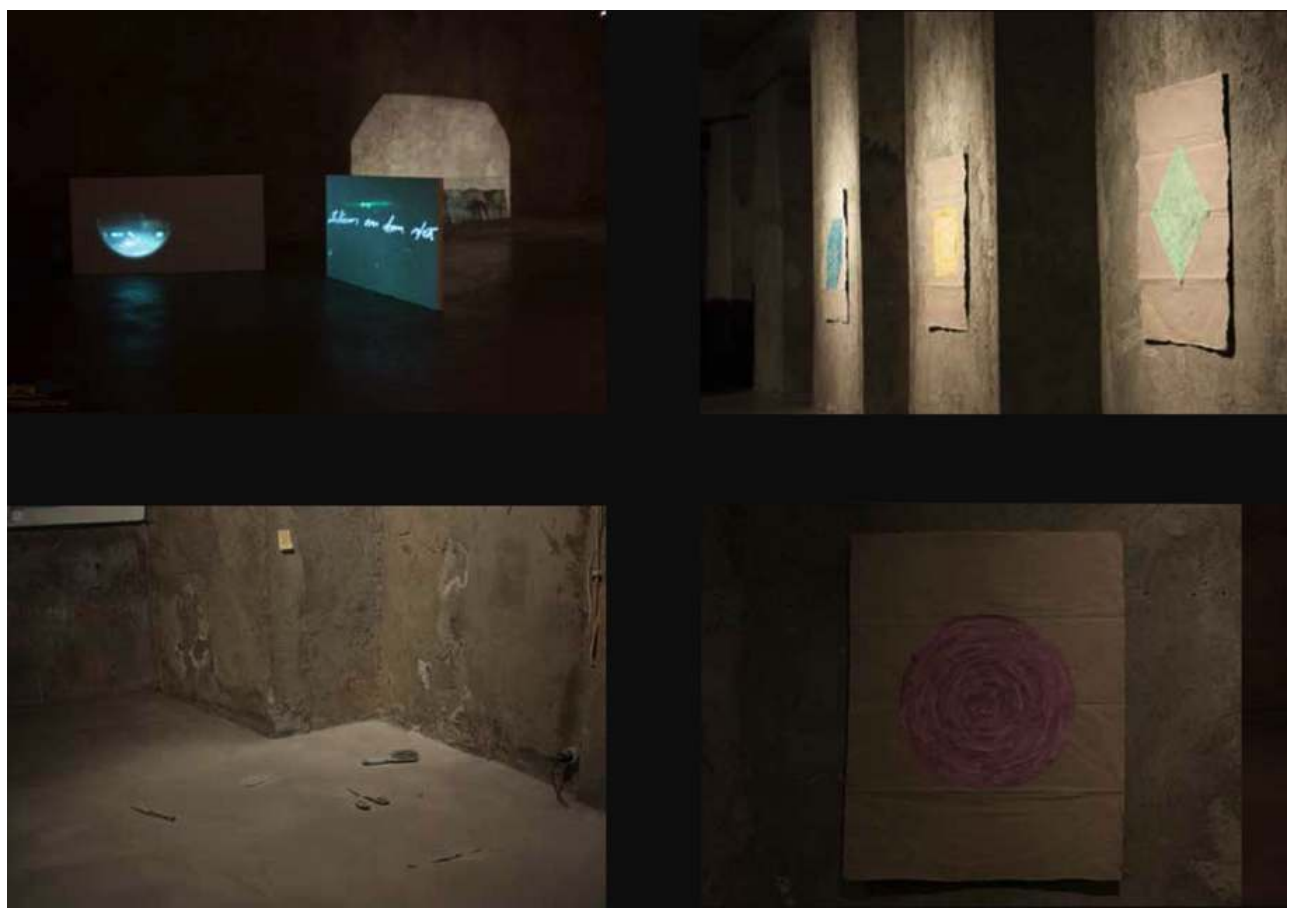

Fig. 3 - Maria Manuela Lopes, 2012, The Therapy. Exhibition Uma Coisa Entre Muitas. Museu Nacional de Historia Natural e da Ciência, Lisbon

PHOTOGRAPHY BY MARIA MANUELA LOPES @

\section{Collaboration}

By their generosity in allowing me into their research environment, the dementia research neuroscientists have embraced the non-logical, intuitive, humorous and poetic aspects of their tradition. They have also shown a willingness to explore the associative and poetic forms of logic that my artistic process implies. It is therefore possible that science within the field of this disease may evolve in unexpected ways that are allied to greater awareness of philosophical, cultural and historical factors and the myriad possibilities of finding and expressing knowledge. In time, scientists may come to believe that art practice can be a powerful form of research that is complementary to the scientific pursuit of knowledge, and derive examples and practical advantages from this. 
41 Doing arts-based research in a scientific residency and distinct groups of investigation implied negotiating the interests of the involved institutions, schedules, bureaucracies, funding, and most of all the time frame of the patient. My work brings together understandings of the institutional and cultural framing of visual strategies, archiving, assessment methods and therapies. It also interrogates the possible application of neuroscientific practice and inscriptions in a different, more subjective and visual discourse on memory. My practice involved a sense of method, of planning the direction of the making, and of following strategies of mimicking or using assessment guides, but my process unfolds via the cultivation of a sense of openness and readiness to respond to expressive material elements, framing, time and space as they arise during the making and montage process. I emphasize that the resulting installation work embodies the power to communicate complex scientific and human concerns through art, and demonstrates the strength of using aesthetic strategies to present complex notions of disease, memory, archiving, clinic diagnostic and treatment or therapies.

\section{Reflecting on the journey}

Within and across the scientific field, images, gestures and objects require labels and instructions for use, in the form of explanatory or contextual text. These are usually archived and transferred with related images or other visual representations, fundamental epistemic elements in the scientific network. In contrast the circulation of images from science into other spheres follows the rules and guidelines specific to those spheres. When deprived of their associations, however, inscriptions become iconised or recontextualised in novel ways.

My artistic residency involved setting up possibilities, negotiations and conditions under which to initiate and determine directions, as well as addressing questions that arose from my experiments and making new connections between concepts, strategies, material production and experiences. As these processes are not linear or sequential, they were regarded as a series of mapping strategies each of which made use of techniques and concepts of juxtaposition and montage. In terms of archiving strategies, data collection was categorised as 'visual' or 'order' depending on function, inscriptive devices and space, or my strategic division into the four virtual archival spaces.

The starting point for the visual vocabulary was the circulation in the virtual archival spaces and the observation of neuroscientific guidelines, protocols, methods of archiving and practices such as the neuropsychological assessment of patients and refrigeration facilities in the molecular laboratory (fig. 4). Conversations with scientists and medical research members were always part of the construction of decisions and the nature of art practice arose a few times as discussion topic in lab meetings. The method devised facilitated the introduction of my own experience beyond the 'third person' observer of the traditional ethnographer. A language and methodology was developed that differed from most of my other previous works, even those relating to previous art/science residencies and collaborations undertaken during the thesis research period. 


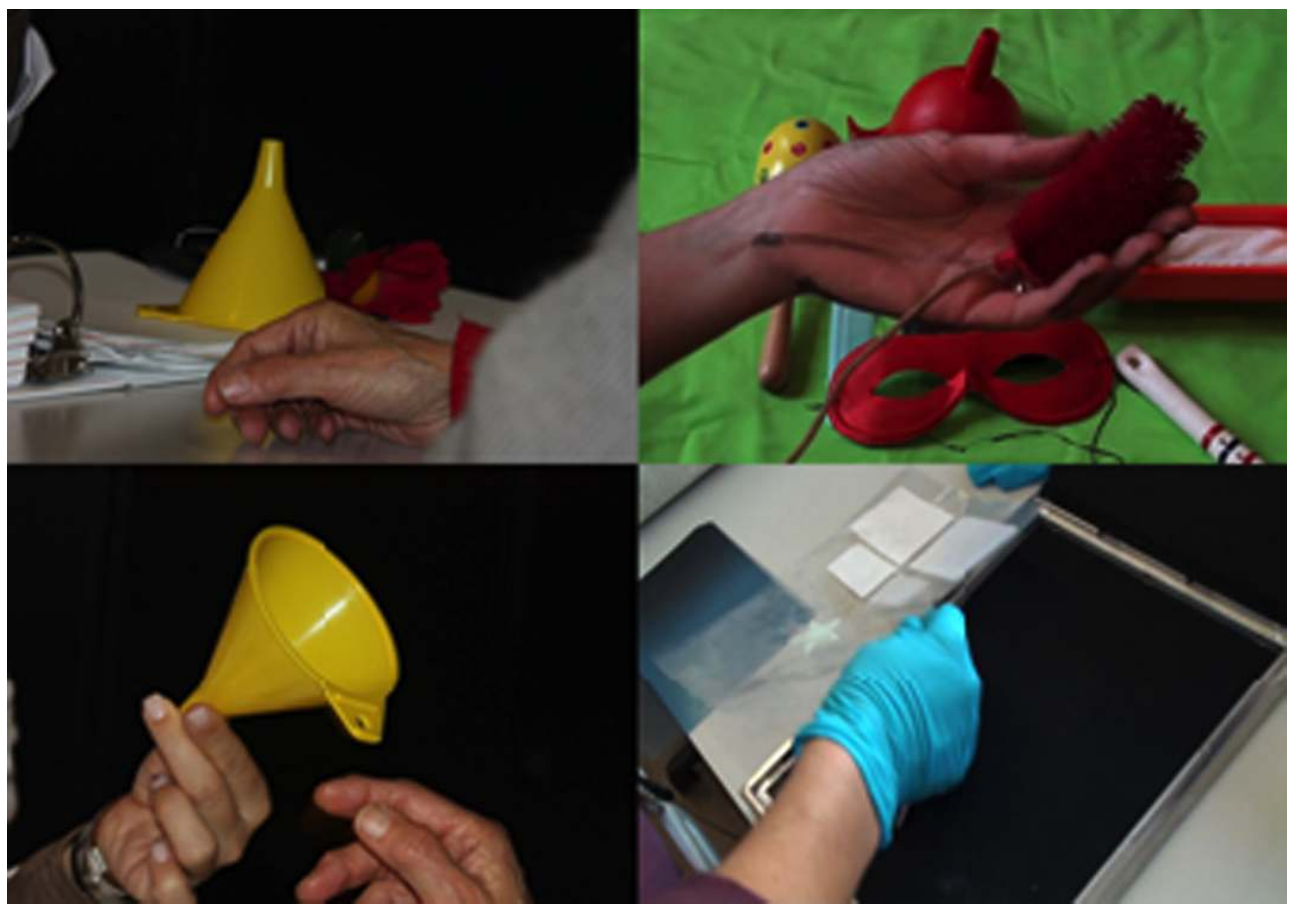

Fig. 4 - Maria Manuela Lopes, 2009. The Four Virtual Archival Spaces. Detail of representational strategies as assessing practices

Photography by Maria Manuela Lopes (c)

My method and the resulting installations, which reveal some of the inescapable complexities and irrational aspects of memory and neuroscience, have elicited a wide spectrum of responses from the various people who have experienced them; some engaged enthusiastically, while others reacted defensively or suspiciously. ${ }^{13}$

While treading the line between revelation and concealment I aim to be authentic about my intentions and my aim of bridging the gap(s) between the fields of neuroscience and art practice. At present, there seem to be too many overlaps: what I initially believed was a fine line separating the domains has expanded into an invisible network of people, actions, time and context. As a result, I now feel that the only appropriate method of presenting the juxtaposed and multimodal construction seen in the installations is the montage as a process. Because the margins overlap, I no longer need a bridge but a code which may be turn out to be the passage of time plus a predisposition to an open heart by which to gain meaning and be moved. 


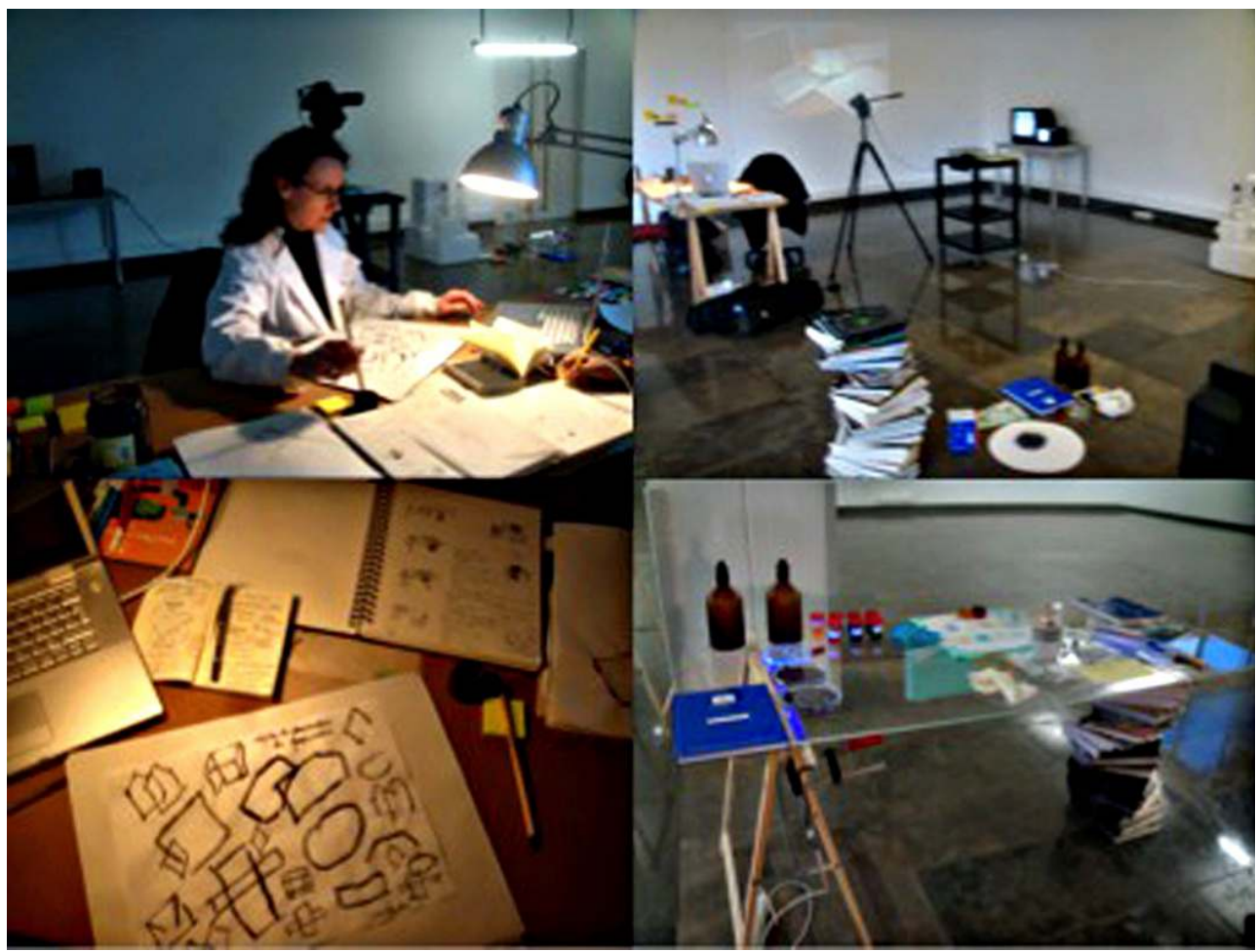

Fig. 5 - Maria Manuela Lopes, 2011, The Archive: Enactment/Re-Enactment of the Archive. Performance at IMM (Instituto de Medicina Molecular), 18-25 March, Lisbon

Photography by Maria Manuela Lopes (c)

47 As an artist I close the loop by feeding back into the wider culture - if not with an explicit revelation of the kind for which scientists strive, at least with a willingness to contemplate new forms of knowledge. This is to be achieved using visual and sound languages that are not explicitly bound by the laws of empiricism and logic, but are rather strategies that emphasise play, dialectics, drama, humour, and ambiguity as paths to evoke autobiographical memory. There is encouraging evidence that scientific researchers are also attempting to open up dialogues and collaborate with artists in order to build on and share knowledge and cast a new light on their own work. This became evident during my diverse public presentations and informal discussions. New and useful connections have been made to my practice as research, and to its broader contribution to the interdisciplinary field, by engaging with practice and theory as process and strategy rather than paradigm, and with the works of other artists whose thinking has helped me to articulate this approach. Science communication departments were a valuable contribution in the validation of the artistic practices (fig. 5) and the establishing of endurable collaborations. 


\section{BIBLIOGRAFIA}

Alač, Morana. 2006. "How Brain Images Reveal Cognition: An Ethnographic Study of MeaningMaking in Brain Mapping Practice.” Cognitive Science PhD dissertation, University of California. Berg, Marc, and Annemarie Mol, eds. 1998. Differences in Medicine: Unravelling Practices, Techniques and Bodies. Durham: Duke University Press.

Conway, Martin. A. 2005. "Memory and the Self." Journal of Memory and Language 53 (4):594-628.

Elkins, James. 2008. Six Stories from the End of Representation: Images in Painting, Photography, Astronomy, Microscopy, Particle Physics, and Quantum Mechanics, 1980-2000. Stanford: Stanford University Press.

Kemp, Martin. 2009. “Dissecting The Two Cultures.” Nature 459 (May): 32-33.

Kemp, Martin. 2011. “Artists in the lab.” Nature 477 (September): 278-279.

Latour, Bruno 1987. Science in Action: How to Follow Scientists and Engineers Through Society. Cambridge: Harvard University Press.

Latour, Bruno. 1998. "How to Be Iconophilic in Art, Science, and Religion?" In Picturing Science, Producing Art, edited by Caroline A. Jones, Peter Gallison, and Amy E. Slaton, 419-440. London: Routledge.

Latour, Bruno. 2005. Reassembling the Social: An Introduction to Actor-Network-Theory. Oxford: Oxford University Press.

Latour, Bruno, and Steve Woolgar. 1986. Laboratory Life: The Construction of Scientific Facts. Princeton: Princeton University Press.

Lopes, Maria Manuela. 2013. “Representational Strategies on Alzheimer's Disease: A Practice Based Arts Research in a Neuroscience Laboratory." PhD thesis, University of Brighton and University for the Creative Arts.

Lynch, Michael, and Steve Woolgar. 1990. "Introduction: Sociological Orientations to Representational Practice in Science." In Representation in Scientific Practice, 1-18. Cambridge: MIT Press.

Snow, Charles P. 1959. The Two Cultures. Cambridge: Cambridge University Press.

Sturken, Marita, and Lisa Cartwright. 2002. Practices of Looking: An Introduction to Visual Culture. 2nd ed. Oxford: Oxford University Press.

Tulving, Endel. 1972. "Episodic and Semantic Memory." In Organization Of Memory, edited by Endel Tulving, Wayne Donaldson, and Gordon H. Bower, 381-403. New York: Academic Press.

Tulving, Endel. 2002. “Episodic Memory, From Mind To Brain.” Annual Review of Psychology 53: $1-25$.

van Dijck, José. 2002. “After the 'Two Cultures': Towards a '(Multi)cultural' Practice of Science Communication." Paper presented at the Conference Public Communication of Science and technology, Capetown, South-Africa, 4-7 December, 1-15. 


\section{NOTAS}

1. This research was funded by grants from the FCT - Portuguese Foundation for Science and Technology (e.g. SFRH/BD/37721/2007 and SFRH/BPD/98356/2013).

2. The proactive search for partner depended on the network I established. I was the first artist in residence at ECTOPIA (first official art/science residency program in Portugal - I later joined as co-director) at Instituto Gulbenkian de Ciência, and from then on I have participated in several other art/science residencies nationally and internationally.

3. To exhibit an art project it requires the coordination of some departments and as a consequence funds are required to make possible the installation and display of the works. Communicators of science inside institutions are valuable help once they usually deal with questions related to construction, understanding and promotion of ideas and visual imagery, but also with suggestions for budgeting, financial support, facilities, institutional assistance and public relations, thus transforming the complex logistics into something more attainable. Therefore, in my experience, when a collaboration is established between an artist and a team of scientists the communication of science department should be involved once they may be of valuable collaborators not just by the aforementioned but also due to their capacity of envisioning the translation of languages, and processes into metaphors and in a comparable position as an art curator might ignite the validity and creation of knew knowledge neither in the field of arts nor in the field of sciences.

4. Assessments included: 1) A thorough clinical history that follows the evolution of symptoms; 2) Neuropsychological examination to assess the degree of cognitive decline; 3) Neurological examination to identify specific signs; 4) A complementary investigation that includes laboratorial and image-based examinations such as MRI and CT scans. Therapy included: infusion of trial drug and diverse cognitive stimulation strategies and follow up consultation dn clinical/ psychological assessment.

5. In Science in Action Latour discusses the constructed nature of science and how reality is a reenactment in the laboratory: 'Showing' and 'seeing' are not simple flashes of intuition. Once in the laboratory we are not presented outright with the real [...] whose existence we doubted. We are presented with another world in which it is necessary to prepare, focus, fix and rehearse the vision of the real [...] We came to the laboratory in order to settle our doubts about the paper, but we have been led into a labyrinth $(1987,67)$.

6. This specialized way of knowing reinforces Foucault's power/knowledge discourse to provide a hierarchy by which to assess the understanding of a disease. We are so used to privileged access to discursive practices and authority structures that we seek constantly to confirm and validate feelings, understandings and practice via the doctor, art critic, curator or members of the public. 7. The concept of 'translation' is used to a practical end: anyone who needs to construct a fact must involve other people and technologies, but must simultaneously control their performances.

8. Representational strategies addressed are not limited to the visual; they can be anything that is a conduit for a message. They may include gestures, elements of language, spaces and experiences in time.

9. In order to record patients, ethics approval was required from both institutions involved, following the generic principles of arts and humanities research and considering legal liability, honest and open practice and moral responsibility. In order to conduct my research at PhD level, and as part of a bid to establish the validity of fine art research alongside scientific knowledge, it 
was necessary to bridge ethical chasms between different scientific and artistic disciplines and external research and funding centres. This represented In terms of science and medicine a permanent philosophical reflection (resulting in practical norms, codes of practice and informed consents), while in terms of art seeming to imply a fluid negotiation between subject and object (producers, promoters and audiences) grounded in volatile agreements that are contextually changeable.

10. Alač (2006), and Latour and Woolgar (1986) have demonstrated in their laboratory work on image learning processes that the often-unseen details of the scientific world are embedded in ordinary gestures and generic interactional practices. Gaining knowledge consists of an active involvement of gesture, talk, gaze, body orientation, and the historically built material world.

11. I suggest that through the construction of the therapy installation environment, using elements of narrative in a non-linear play by repetition in parallel with objects, I am able to create this space of action for the participant, thus approaching the subjective, permanently constructed zone. My installation work is more than an idea of my own story within laboratorial exploration; it is an invitation to the observer to participate, and to explore a specific environment and therapeutic strategies, through processes more or less conducive to supporting the unfolding of an approach to my understanding of autobiographical memory.

12. Re-enactment differs from the original event, but it may presume or critique the authentic nature of its referent. Access to its referent is mediated through memory traces, which inevitably form an incomplete and untrustworthy model for it's restaging. It therefore becomes what those re-enacting it want it to be.

13. During my various presentations I have encountered a degree of apprehension from those few ones who were unfamiliar with the language of installation, media arts or of the scientific signs used. When, however, I explained that I was conducting a research project involving Alzheimer's disease, many of these people engaged with the project and asked questions. Some scientists may have been unwilling to let go of their rigidly empirical stance, or may simply have been reluctant to try to understand why anyone wanted metaphorically to 'reshuffle the cards' that they had just taken the time to separate into pairs of numbers. As my research also interrogates the possible application of neuroscientific practice and inscriptions in a different, more subjective and visual discourse on memory some scientists were more reserved on their engagement with the purpose of the project.

\section{RESUMOS}

As an artist I pursue a transdisciplinary practice and my process evolves and takes place in time, in different contexts and through distinct materials. The collaboration between artists and scientists is no longer a surprise and is validated as a strategy by many differing authors. However, the proposed inquiry to reflect on the working relationships between artists, scientists and communicators of science, in the process of art production, became a challenging task. Through the analyses of the production of an art installation (The Therapy) developed in the context of my $\mathrm{PhD}$ research during an artistic residency in neuroscience laboratories and a 
hospital, I devised an approach that touches issues of authorship and collaboration, and coconstruction of knowledge and meaning in a relational network. In creative terms, the major conclusions are the development of several novel methods of research, the resulting artefacts and the practical materialization of these via the agency of installation.

Como artista desenvolvo uma prática interdisciplinar e o meu processo evolui e toma forma no tempo, em diferentes contextos e em distintos suportes/matérias. A colaboração entre artistas e cientistas não é mais uma surpresa e é validada por vários autores como estratégia no mundo artístico. No entanto, o repto proposto de refletir sobre as relações de trabalho entre artistas, cientistas e comunicadores de ciência, no processo da produção artística, tornou-se uma tarefa desafiante. Através da análise da produção de uma instalação artística (A Terapia) desenvolvida no contexto do meu projeto de doutoramento, quando em residência artística em laboratórios de neurociências e num hospital, delineei uma proposta que toca em questões de autoria e colaboração e co-construção de conhecimento e significados numa rede relacional. Em termos criativos as maiores conclusões foram o desenvolvimento de vários métodos inovadores de investigação, os artefactos resultantes e a materialização prática deles via instalação.

\section{ÍNDICE}

Keywords: science and art, neuroscience, memory, Alzheimer's disease

Palavras-chave: ciência e arte, neurociência, memória, doença de Alzheimer

\section{AUTOR}

\section{MARIA MANUELA LOPES}

Visual artist and researcher based in Portugal and in the United Kingdom. Her current practice is transdisciplinary and is based on issues of memory and self-identity informed by life sciences and medical research, and presented in the form of time-based installations. She has been working, teaching and showing nationally and internationally since 1998. Lopes studied fine arts in Porto and did a master at Goldsmiths College in London. She has a doctorate from the Brighton University, and is doing a post-doc project at the University of Aveiro and University of Oporto (Instituto de Biologia Molecular e Celular). Lopes is assistant-director of two arts/residency programs: Ectopia and Cultivamos Cultura. maria@manuelalopes.com 